\title{
A Model for Enhancing Algorithmic Thinking in Programming Education using PAAM
}

\author{
https://doi.org/10.3991/ijim.v15i09.20617 \\ Sohail Iqbal Malik $\left.{ }^{(}\right)$, Ragad M Tawafak, Ghaliya Alfarsi, \\ Mohammed Waseem Ashfaque, Roy Mathew \\ Al Buraimi University College, Al-Buraimi, Oman \\ sohail@buc.edu.om
}

\begin{abstract}
Most novice programmers consider learning to program as a difficult and challenging field of study for them. As a result, high dropout and failure rates in programming one courses reported. One of the reasons is that most programming (1) courses don't give equal attention to syntax and semantics of programming language and algorithmic thinking. In this study, a web application based on Problem Analysis and Algorithmic Model (PAAM) was prepared and acquainted in the programming (1) course. The application focuses on problem analysis and algorithmic thinking. The influence on genders' opinion after offering the PAAM model in the programming (1) course determined by organizing a survey. The mean values of the male and female survey respondents compared by performing the T-test. The purpose is to determine if there is any significant difference between the mean values. Results show that students appreciated the web application in the programming (1) course. Male students discerned more positive responses in the survey questions compared to female students. The T-test result shows a significant difference between the values of respondents because the p-value for equal variances assumed is (.000), which is less than $\mathrm{p}=0.05$. The application encourages a new approach based on four steps (problem statement $\rightarrow$ problem analysis $\rightarrow$ problem-solving skills $\rightarrow$ code) for novices. The application helps students to understand programming structures, program design and comprehension.
\end{abstract}

Keywords - Algorithmic thinking, E-learning, introductory programming, novice programmer

\section{$1 \quad$ Introduction}

Most novice programmers consider learning to program a problematic and challenging field of study for them [1]. Students have to simultaneously emphasize different skills, such as algorithmic thinking, program design, and structures [2]. On the other hand, further research studies [3][4][5] concluded that most programming (1) courses give more attention to syntax and semantics compared to algorithmic thinking. Consequently, novice programmers cannot write a good program, although they have a good understanding of programming language (syntax and semantics) [2]. Moreover, most programming (1) textbooks present the content related to syntax and 
semantics of programming languages [6]. Therefore, reference [7] suggested offering algorithmic thinking as a primary objective for computer science education students.

This study prepared and introduced the PAAM-based web application in the programming (1) course. The application focuses on problem analysis and algorithmic thinking. The PAAM model uses IPO (input, process and output) for problem analysis. The algorithmic thinking presented by pseudo-code technique. A survey was organized with students after offering the PAAM model in the teaching-learning process of the programming (1) course. The mean values of the male and female survey respondents compared by performing the T-test. The purpose is to determine if there is any significant difference between the mean values.

The paper divided into different sections. The background presented first, which followed by a research question of this study. The web-based application based on the PAAM model explained briefly. The next section describes the research methodology, followed by the results of this study. A brief discussion provided, and finally, the summary of this study presented.

\section{Background}

Algorithmic thinking described as a process to solve a given problem by proposing a sequence of steps in a specific order [8]. Therefore, it is considered an essential concept to be taught to computer science students and related fields [9]. On the other side, if the students don't have a background in algorithmic thinking, they are considered handicapped in higher studies [10]. Moreover, students don't acquire these skills appropriately by using these traditional teaching strategies. Thus, reference [10] suggested that algorithmic thinking should consider as a strategic focus in an educational field.

Learning to the program should focus equally on different programming language skills such as syntax, algorithmic thinking, and semantics [11]. Further studies [3][4][5] concluded that most programming (1) courses focus more on semantics and syntax compared to algorithmic thinking. Reference [30] suggested pair programming is more effective than solo programming for novice programmers in secondary education. Reference [32] introduced a didactic approach based on multiple technologies (Twitter, Python, and Arduino) for teaching basic concepts of programming to novice programmers.

Reference [9] suggested that algorithmic thinking should offer from the beginning of the programming domain's teaching-learning process. Turtle Graphics Tutorial System (puzzle-based game) developed and introduced to promote algorithmic thinking [12]. Reference [13] introduced Alice, an educational environment, to promote algorithmic thinking. Contact [14] promoted algorithmic thinking in the programming (1) course by offering a new ADRI (Approach, Deployment, Result, Improvement) model. Reference [15] prepared and submitted a mobile app and a web-based application of the 'PROBSOL' in the programming (1) course to promote algorithmic thinking. Results show that the applications improve students' logic capabilities, programming understanding and algorithmic thinking skills [16]. References 
[28][29][33][35][36] introduced 'Scratch', 'ScratchJr' and 'App inventor' as tools in the teaching-learning process of science education to enhance computational thinking and a basic understanding of programming education of novice programmers. Furthermore, references [31][34] concluded that a game-development approach positively impacts the basic programming concepts of CS courses students.

\section{$3 \quad$ Research Question}

The previous section depicts that learning to program is a problematic and challenging task for novices in the programming (1) course. Therefore, we prepared and offered the PAAM-based web application in the programming (1) course. This study proposes a research question to determine the influence of the PAAM model on novices.

The study addressed the following research question:

- RQ1: How does the PAAM model influence the opinion after introducing it in the programming (1) course?

\section{Web-Based Application of PAAM Model}

The PAAM-based web application introduced in the programming (1) course to promote algorithmic thinking among novice programmers. The interface of the PAAM-based web application shown in figure 1 . 


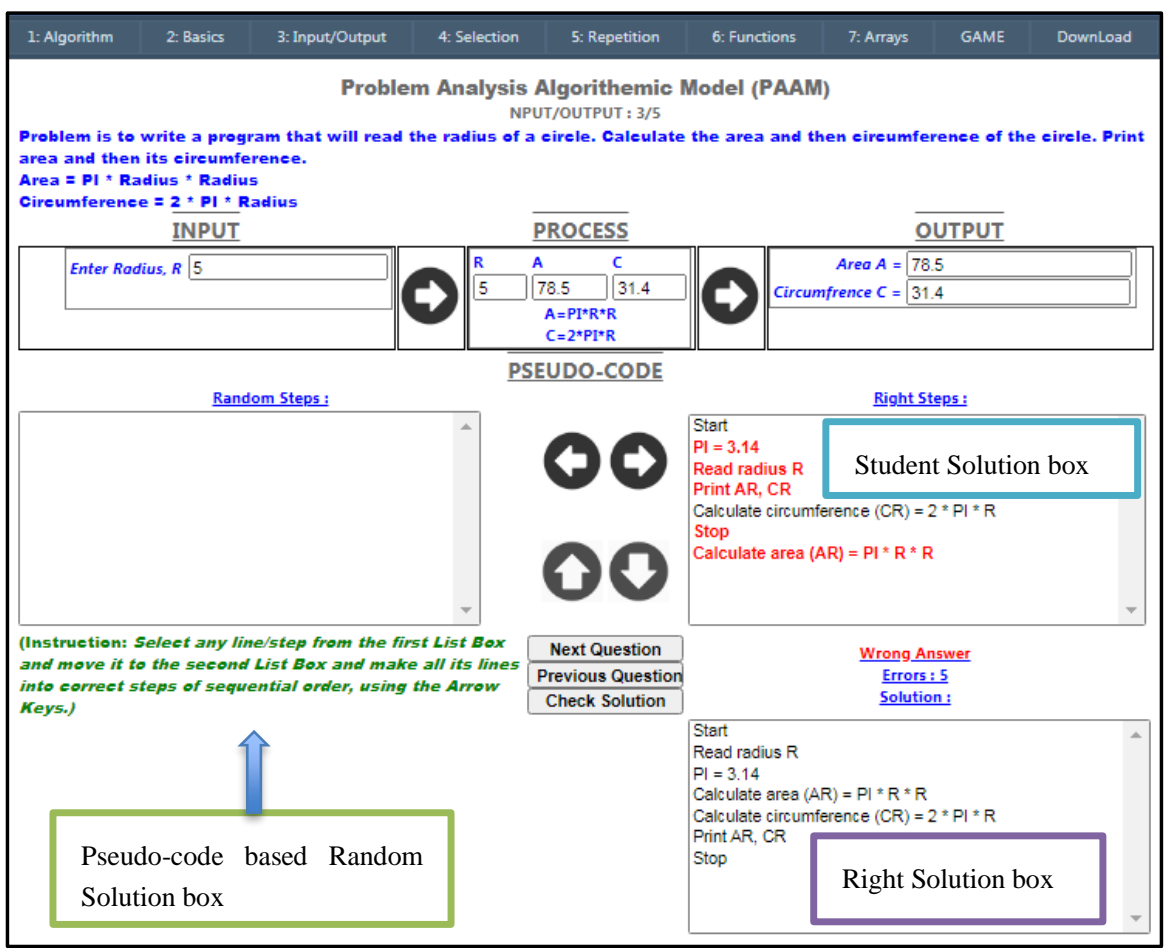

Fig. 1. The interface of the Web-based PAAM application

Most teaching topics of the programming (1) course are covered by the application, as shown in figure 1. 3 to 5 questions added in the application for each topic. A given problem statement is provided at the top of the application for each question, as shown in figure 1.

The PAAM model focuses on problem analysis and algorithmic thinking in this application. For the problem analysis, students have to concentrate on IPO (Input, Process and Output) related to the given problem question as depicted in figure 1. Students will enter the input required by the given problem statement. By clicking the buttons provided in the application, students can see the process needed to solve the given problem statement and the program's output.

For algorithmic thinking, three list boxes given in the application, as shown in figure 1. Pseudo-code based Random steps of the given problem question provided in the 'Pseudo-code based Random solution box'. Students can move their proposed solution in the 'Student Solution box' from the 'Pseudo-code based Random solution box' by clicking the application's buttons. Students can check their answer by clicking the 'Check Solution' button when all the solution steps moved in the 'Student Solution box'. The 'Right solution box' shows the correct steps of the given problem question, as shown in figure 1. 
The application also shows the total number of errors in the student's proposed solution. Moreover, the student's proposed solution's wrong steps also shown in red color in the 'Student Solution box' as shown in figure 1.

Students either choose next or previous questions by clicking the buttons or by through the menus provided in the application.

\section{$5 \quad$ Research Methodology and Design}

The impact tested on the perception after offering the PAAM model in the programming (1) course determined by organizing a survey. Eighty-eight students submitted their responses in the survey. Out of 88 students, 40 participants $(45.5 \%)$ were male, and the remaining $(54.5 \%)$ were female students. Ethical approval obtained from the college before collecting the data. Moreover, participation in the survey was anonymous and volunteered for students.

The survey consists of thirty-one questions. The first part includes five demographic questions. The second part covers thirteen questions emphasized the PAAM model's usability in the programming (1) course. The third part consists of six questions, which emphasize the programming concepts. The last part contains six questions highlighted on the PAAM model's suitability in the programming (1) course. All the problems of the survey listed in figures three, four and five below. Most of the questions in second, third and last parts taken from reference [17].

\section{$6 \quad$ Result}

The survey conducted to collect the perceptions of genders regarding the impact of PAAM model in the programming (1) course. The mean values of the male and female survey respondents compared by performing the T-test. The purpose is to determine if there is any significant difference between the mean values. Results of the Ttest shown in Table 1.

Table 1 shows a significant difference between male and female respondents' values because the $\mathrm{p}$-value for equal variances assumed is $(.000)$, which is less than $\mathrm{p}=$ 0.05 .

Table 1. T-test results of survey responses

\begin{tabular}{|c|l|c|c|c|c|c|}
\hline \multirow{3}{*}{ Mean } & Gender & $\mathbf{N}$ & Mean & Std. Deviation & Std. Error Mean & Significance value $(\mathbf{P})$ \\
\cline { 2 - 7 } & Female & 25 & 3.7840 & .15313 & .03063 & .000 \\
\cline { 2 - 7 } & Male & 25 & 4.1472 & .21648 & .04330 & Equal variances assumed \\
\hline
\end{tabular}

Table 2 shows the demographic details of the participants. 
Table 2. Demographic details of participants

\begin{tabular}{|c|c|c|c|c|}
\hline No. & Area & Sub-Area & Female $(\%)$ & Male (\%) \\
\hline \multirow[t]{3}{*}{1} & \multirow[t]{3}{*}{ Major } & Information Systems & $47.9 \%$ & $25.0 \%$ \\
\hline & & Software Engineering & $31.3 \%$ & $40.0 \%$ \\
\hline & & Computer Science & $20.8 \%$ & $35.0 \%$ \\
\hline \multirow[t]{3}{*}{2} & \multirow[t]{3}{*}{ Degree } & Bachelor & $54.2 \%$ & $45.0 \%$ \\
\hline & & Advanced Diploma & $12.5 \%$ & $5.0 \%$ \\
\hline & & Diploma & $33.3 \%$ & $50.0 \%$ \\
\hline \multirow[t]{4}{*}{3} & \multirow[t]{4}{*}{ Age } & Under 18 years & $6.3 \%$ & $5.0 \%$ \\
\hline & & 18 to 28 years old & $89.6 \%$ & $90.0 \%$ \\
\hline & & 29 to 44 years old & $4.2 \%$ & $5.0 \%$ \\
\hline & & 45 years old or above & $0.0 \%$ & $0.0 \%$ \\
\hline \multirow[t]{2}{*}{4} & \multirow[t]{2}{*}{ Gender } & Female & $54.5 \%$ & $\mathrm{n} / \mathrm{a}$ \\
\hline & & Male & $\mathrm{n} / \mathrm{a}$ & $45.5 \%$ \\
\hline \multirow[t]{2}{*}{5} & \multirow[t]{2}{*}{ Prior programming experience } & No & $79.2 \%$ & $68.4 \%$ \\
\hline & & Yes & $20.8 \%$ & $31.6 \%$ \\
\hline
\end{tabular}

Figure 2 shows the respondents' perception regarding the 'usability of PAAM model' in the programming (1) course.

Figure 2 depicts that male respondents perceived better than female respondents in 13 different parts. 'Understand the inputs required for the given programming question', 'Understand the process to solve the given programming question', 'Understand the outputs required for the given programming question'. Also, points as 'Understand the given programming question', 'Understand the programming concepts' and 'Learn the pseudo-code technique (problem-solving skills)'.

Besides, 'Emphasize on problem-solving skills', 'Understand programming structures', 'Learn the course contents', 'Design a solution to solve a programming task'. Furthermore, 'Enhance my learning by participating in the course activity', 'Develop my skills related to my academic career and professional life', and 'Develop my confidence in the programming area'. 
Usability of PAAM model

Understand the inputs required for the given problem question

Understand the process to solve the given problem question

Understand the outputs required for the given problem question

Understand the given problem question

Understand the programming concepts

Learn the pseudo code technique (problem solving skills)

Emphasize on problem solving skills

Understand programming structures

Learn the course contents

Design a solution to solve a programming task

Enhance my learning by participating in the course activity

Develop my skills that are related to my academic career and professional life

Develop my confidence in the programming area
Male Female

11011111011104.13 3.96

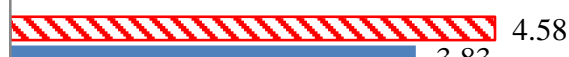
3.83

1101101101101100

3.81

DININININININ 4.13

3.79

1010101010101006035

111111111111111110.35 4.09

110111011011010

3.77

1010101010101005

3.78

101011010101006

3.82

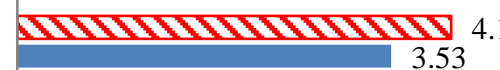

1000100010001000

3.77

1101101101101100

3.69

110111111111104.18

Fig. 2. Usability of PAAM model

Figure 3 shows the respondents' perception of the third part of the survey, including 'programming concepts' questions. 


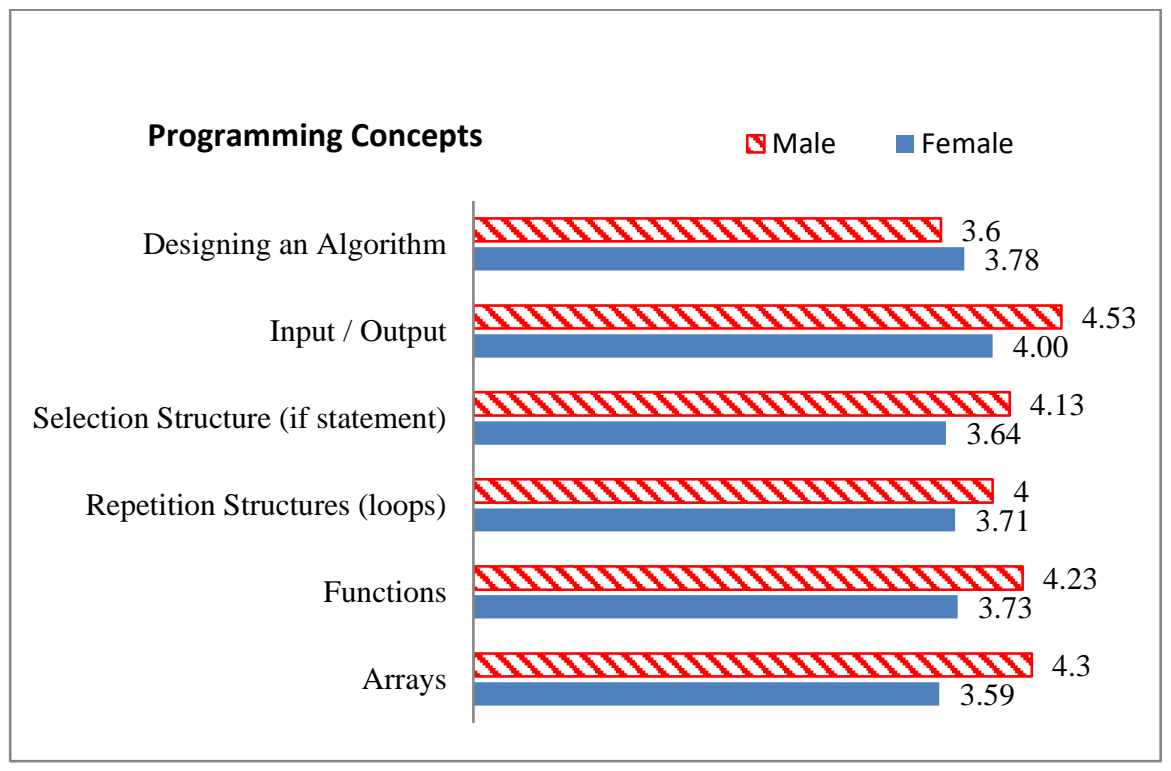

Fig. 3. Programming concepts

Figure 3 depicts that female students show slightly better responses than male students in 'Designing an algorithm'. For the remaining five questions ('Input / Output', 'Selection Structure (if statement)', 'Repetition Structures (loops)', 'Functions' and 'Arrays') of this section, male students show better responses than the female students.

Figure 4 depicts the respondents' perception of the last part of the survey. 


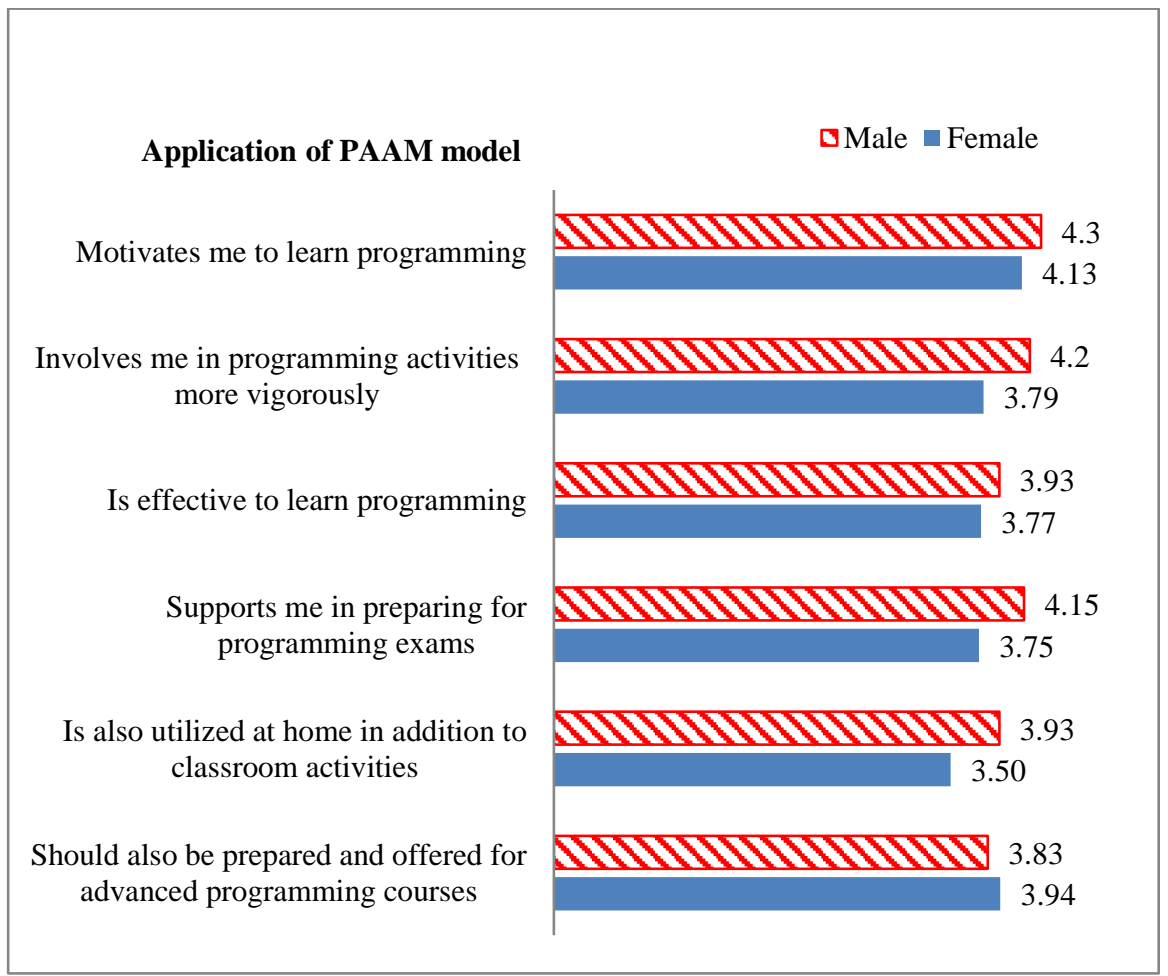

Fig. 4. Application of PAAM model

As shown in figure 4, male students show better responses than their counterpart female students in 'Motivates me to learn to program', 'Involves me in programming activities more vigorously', 'Is effective to learn to program', 'Supports me in preparing for programming exams', and 'Is also utilized at home in addition to classroom activities'. On the other side, female students show better responses than male students in 'Should also be prepared and offered for advanced programming courses'.

\section{$7 \quad$ Discussion}

The survey results depicted that both male and female students appreciated the web-based application of the PAAM model in the IP course. The PAAM model focuses on problem analysis and problem-solving skills for novice programmers. Different studies [18][19][20] suggested that these skills are essential for novice programmers and should be given special attention in the IP course.

The survey results show that female students perceived less positive responses than male students in most of the questions. Reference [37] concluded that female students lack self-confidence compared to male students. Moreover, this finding is consistent with [11][38], which also finished that male students show more confidence in learning programming than female students. 
The application discourages programming shortcut [21] (problem statement $\rightarrow$ code) and encourages a new approach based on four steps (problem statement $\rightarrow$ problem analysis $\rightarrow$ problem-solving skills $\rightarrow$ code). This process promotes in-depth learning of the programming domain and helps novices to emphasize on program design skills. This finding is consistent with [22], who introduced the ADRI model in programming education to discourage programming shortcuts.

The survey result shows that both male and female students appreciated that the web-based application of the PAAM model helped them understand the structures of the programming language. Moreover, it helped them in developing design skills for solving the given problem statement. This finding is consistent with reference [23].

Both female and male students agreed that the application helped them in understanding different programming concepts. Pseudo-code technique use to solve the programming questions that support novices in understanding programming concepts without paying much attention to the syntax. This finding is consistent with references [24] [25].

Both male and female students agreed that the PAAM model's application motivated them to learn to program. Moreover, the application supported them to prepare the programming exams. This process helps computer science and related departments retain students, which considered a significant issue in this field. Reference [26] argued that students would likely discontinue computer science studies if they fail or pass the programming (1) course with a struggle.

\section{Conclusion}

The study introduced a PAAM-based web application in the programming (1) course for novice programmers. The application focused on problem analysis and problem-solving skills in the class.

Results of the survey revealed that both female and male students appreciated the application in the IP course. The application helped them in understanding the given problem statement requirements (input, process and output). Furthermore, it supported them in understanding programming structures and program design skills. The T-test result shows a significant difference between the values of male and female respondents because the p-value for equal variances assumed is (.000), which is less than $p=$ 0.05 . Male students discerned more positive responses in the survey questions compared to female students.

The application provides 3 to 5 questions for each teaching topic covered in it, supporting novices to understand programming concepts. Moreover, it offers beginners to practice algorithmic thinking for most of the semester.

Students agreed that the application motivated them to learn to program and helped them to prepare programming exams. The application is web-based which enabled them to access and finish their programming exercises outside the class setting.

In the future work, the web application will update with artificial intelligence features such as chatbot and intelligent tutoring systems etc. Reference [27] suggested that these features positively impact the teaching-learning process of the students. 


\section{$9 \quad$ References}

[1] Malik, S. I., Al-Emran, M., Mathew, R., Tawafak, R. M., \& AlFarsi, G. (2020). Comparison of E-Learning, M-Learning and Game-based Learning in Programming Education: A Gendered Analysis. International Journal of Emerging Technologies in Learning, (15). https://doi.org/10.3991/ijet.v15i15.14503

[2] L.E., Winslow, "Programming pedagogy - a psychological overview", ACM SIGCSE Bulletin, Vol. 28, No. 3, pp.17-22, 1996. https://doi.org/10.1145/234867.234872

[3] H., Wang, I., Huang, and G. Hwang, "Comparison of the effects of project-based computer programming activities between mathematics-gifted students and average students". Journal of computers in education, Vol. 3, pp. 33-45, 2016. https://doi.org/10.1007/s40692$\underline{015-0047-9}$

[4] S.I., Malik, and J., Coldwell-Neilson, "A model for teaching an introductory programming course using ADRI", Education and Information Technologies, Springer, vol. 22, issue 3, pp. 1089-1120, https://doi.org/10.1007/s10639-016-9474-0

[5] S., Iqbal, and O.k., Harsh, "A self-review and external review model for teaching and assessing novice programmers", International Journal of Information and Education Technology, Vol. 3, No. 2, 2013, pp. 120-123. https://doi.org/10.7763/ijiet.2013.v3.247

[6] A., Robins, J., Rountree, and N., Rountree, "Learning and teaching programming: A review and discussion", Computer Science Education, vol. 13, issue 2, pp. 137-172, 2003. https://doi.org/10.1076/csed.13.2.137.14200

[7] J., Hromkovic, T., Kohn, D., Komm, and G., Serafini, Examples of Algorithmic thinking in Programming Education, Olympiads in Informatics, vol. 10, pp. 111-124, 2016. https://doi.org/10.15388/ioi.2016.08

[8] Z., Katai, "The challenge of promoting algorithmic thinking of both sciences and humanities-oriented learners". Journal of Computer Assisted Learning, vol. 31 issue 4, pp. 287299, 2014. https://doi.org/10.1111/jcal.12070

[9] J., Hromkovic, T., Kohn, D., Komm, and G. Serafini, "Algorithmic thinking from the Start", The Education Column, Retrieved from, http://bulletin.eatcs.org/index.php /beatcs/article/view/478, 2019.

[10] G., Kiss, and Z., Arki, "The influence of game-based programming education on the algorithmic thinking”. Procedia - Social and Behavioral Sciences, vol. 237, No. 21, pp. 613617, 2017. https://doi.org/10.1016/j.sbspro.2017.02.020

[11] I.S., Malik, R., Mathew, R. M., Tawafak, and I. Khan, "Gender Difference in Perceiving Algorithmic thinking In an Introductory Programming Course", EDULEARN19 Proceedings, pp. 8246-8254, 2019. https://doi.org/10.21125/edulearn.2019.2042

[12] H., Chih-Chao, and W. Tzone-I, "Applying game mechanics and student-generated questions to an online puzzle-based game learning system to promote algorithmic thinking skills", Computers \& Education, vol. 121, pp. 73-88, 2018. https://doi.org/10.1016/ j.compedu.2018.02.002

[13] S., Cooper, W., Dann, and R., Pausch, "Developing Algorithmic thinking with Alice", In Proceedings of ISECON 2000, Philadelphia, PA, Nov. pp. 9 - 12, 2000.

[14] I.S., Malik, and J. Coldwell-Neilson, "Impact of a new teaching and learning approach in an introductory programming course", Journal of Educational Computing Research, SAGE, vol. 55, issue 6, pp.789-819, 2017. https://doi.org/10.1177/0735633116685852

[15] SI. Malik., R. Mathew M.M. Hammood, "PROBSOL: A Web-Based Application to Develop Problem-Solving Skills in Introductory Programming". In: Al-Masri A., Curran K. (eds) Smart Technologies and Innovation for a Sustainable Future. Advances in Science, 
Technology \& Innovation (IEREK Interdisciplinary Series for Sustainable Development). Springer, 2019, pp 295-302, https://doi.org/10.1007/978-3-030-01659-3 34

[16] S.I., Malik, R., Mathew, R., Al-Nuaimi, A., Al-Sideiri, and J. Coldwell-Neilson, "Learning problem solving skills: Comparison of E-learning and M-learning in an introductory programming course". Education and Information Technologies, 24, 2779-2796, 2019, https://doi.org/10.1007/s10639-019-09896-1

[17] R., Mathew, S.I., Malik, and R.M. Tawafak, "Teaching Problem Solving Skills using an Educational Game in a Computer Programming Course", Informatics in Education, Vol. 18 No. 2, pp. 359-373, 2019. https://doi.org/10.15388/infedu.2019.17

[18] B., Douadi, B., Tahar, and S., Hamid, "Smart edutainment game for algorithmic thinking", Procedia - Social and Behavioral Sciences, 31, 2012, pp. 454 - 458. https://doi.org/10. 1016/j.sbspro.2011.12.085

[19] SI. Malik, M. Shakir, A. Elbow, and M.W. Ashfaque, "Promoting algorithmic thinking in an introductory programming course", International Jounral of Emerging Technologies in Education, Vol 14, No. 1, 2019. https://doi.org/10.3991/ijet.v14i01.9061

[20] SI. Malik, "Improvements in introductory programming course: action research insights and outcomes", Systemic Practice and Action Research, 2018, Springer. https://doi.org/10.1007/s11213-018-9446-y

[21] M. Webster, Overview of programming and problem solving, Merriam-Webster's Collegiate Dictionary, Tenth Edition, 1994, retrieved on July15, 2013: http://computerscience.jbpub.com/vbnet/pdfs/mcmillan01.pdf

[22] S., Iqbal, "Role of ADRI model in teaching and assessing novice programmers", $\mathrm{PhD}$ thesis, Deakin University, 2016, hdl.handle.net/10536/DRO/DU:30088862

[23] K., Ala-Mutka, "Problems in learning and teaching programming - a literature study for developing visualizations in the codewitz-minerva project", Codewitz needs analysis, retrieved 20/10/2018, http://www.cs.tut.fi/ edge/literature_study.pdf, 2004

[24] G.M.M., Bashir, and ASML, Hoque, "An effective learning and teaching model for programming languages". Journal of Computers in education, 3, 413-437. https://doi.org/ 10.1007/s40692-016-0073-2, 2016.

[25] H., Ting-Chia, and H., Gwo-Jen, "Effects of a Structured Resource-based Web Issue-Quest Approach on Students' Learning Performances in Computer Programming Courses", Journal of Educational Technology \& Society, Vol. 20, No.3, pp.82-94, 2017.

[26] S., Wiedenbeck, D., LaBelle, and V.N.R., Kain, "Factors Affecting Course Outcomes in Introductory Programming" In proceedings of 16th Workshop of the Psychology of Programming Interest Group. Carlow, Ireland, April 2004, 97-110

[27] M. W., Ashfaque S., Tharewal S. I. Malik, and C. N. Kayte, "A Review on Techniques, Characteristics and approaches of an intelligent tutoring Chatbot system", 2020 International Conference on Smart Innovations in Design, Environment, Management, Planning and Computing (ICSIDEMPC), Aurangabad, 2020, pp. 258-262, https://doi.org/10.1109/ icsidempc49020.2020.9299583

[28] M., Kalogiannakis, and S. Papadakis, "A proposal for teaching ScratchJr programming environment in preservice kindergarten teachers." In Proceedings of the 12th Conference of the European Science Education Research Association ESERA, pp. 21-25, 2017.

[29] M., Kalogiannakis, and S. Papadakis, "Pre-service kindergarten teachers' acceptance of "ScratchJr" as a tool for learning and teaching computational thinking and Science education." In Proceedings of the $12^{\text {th }}$ Conference of the European Science Education Research Association (ESERA), Research, practice and collaboration in science education, pp. 21$25,2017$. 
[30] S. Papadakis, "Is pair programming more effective than solo programming for secondary education novice programmers? A case study" International Journal of Web-Based Learning and Teaching Technologies (IJWLTT), 13(1), pp. 1-16, 2018. https://doi.org/10.4018/ ijwltt.2018010101

[31] S. Papadakis, "Evaluating a game-development approach to teach introductory programming concepts in secondary education." International Journal of Technology Enhanced Learning, 12(2), pp. 127-145, 2020. https://doi.org/10.1504/ijtel.2020.106282

[32] V., Orfanakis, and S. Papadakis, "Teaching basic programming concepts to novice programmers in secondary education using Twitter, Python, Ardruino and a coffee machine." In Hellenic Conference on Innovating STEM Education (HISTEM), pp. 16-18, 2016.

[33] S., Papadakis, and M. Kalogiannakis, "Evaluating a course for teaching advanced programming concepts with scratch to preservice kindergarten teachers: a case study in Greece.” In Early Childhood Education. IntechOpen, 2018. https://doi.org/10.5772 lintechopen.81714

[34] M., Kalogiannakis, and S. Papadakis, "The Use of Developmentally Mobile Applications for Preparing Pre-Service Teachers to Promote STEM Activities in Preschool Classrooms." In Mobile Learning Applications in Early Childhood Education, pp. 82-100, IGI Global, 2020. https://doi.org/10.4018/978-1-7998-1486-3.ch005

[35] S. Papadakis, "Evaluating the efficiency of two programming environments in shaping novices' attitudes, perceptions, beliefs and knowledge in programming: a comparison between Scratch and App Inventor." International Journal of Teaching and Case Studies, 10(1), pp. 31-52, 2019. https://doi.org/10.1504/ijtcs.2019.10017717

[36] S. Papadakis, "Apps to Promote Computational Thinking Concepts and Coding Skills in Children of Preschool and Pre-Primary School Age." In Mobile Learning Applications in Early Childhood Education (pp. 101-121). IGI Global, 2020. https://doi.org/10.4018/9781-7998-1486-3.ch006

[37] A. Funke, M. Berges, A. Mühling, P. Hubwieser, "Gender Differences in Programming: Research Results and Teachers' Perception", Proceedings of the 15th Koli Calling Conference on Computer Education Research, ACM, Finland, 2015. https://doi.org/10.1145/ $\underline{2828959.2828982}$

[38] SI. Malik, and C.N. Jo, "Gender differences in an introductory programming course: New teaching approach, students' learning outcomes, and perceptions", Education and Information Technologies, Springer, 2018, https://doi.org/10.1007/s10639-018-9725-3

[39] Tawafak, R. M., Mohammed, M. N., Arshah, R. B. A., Shakir, M., \& Mezhuyev, V. (2018). Technology enhancement learning reflection on improving Students' Satisfaction in Omani Universities. Advanced Science Letters, 24(10), 7751-7757. https://doi.org/10.1166/asl.2018.13012

[40] Tawafak, R. M., Romli, A. B., bin Abdullah Arshah, R., \& Almaroof, R. A. S. (2018). Assessing the impact of technology learning and assessment method on academic performance. Eurasia Journal of Mathematics, Science and Technology Education, 14(6), 22412254. https://doi.org/10.29333/ejmste/87117

[41] Tawafak, R. M., Romli, A. M., \& Alsinani, M. J. (2019). Student Assessment Feedback Effectiveness Model for Enhancing Teaching Method and Developing Academic Performance. International Journal of Information and Communication Technology Education (IJICTE), 15(3), 75-88. https://doi.org/10.4018/ijicte.2019070106

[42] Tawafak, Ragad M., Awanis Romli, Sohail Iqbal Malik, Mohanaad Shakir, and Ghaliya M. Alfarsi. "A systematic review of personalized learning: Comparison between Elearning and learning by coursework program in Oman." International Journal of Emerging 
Technologies in Learning (iJET) 14, no. 09 (2019): 93-104. https://doi.org/10.3991/ijet.v14i09.10421

[43] Tawafak, Ragad M., Awanis BT Romli, and Ruzaini Bin Abdullah Arshah. "Continued Intention to use UCOM: Four factors for integrating with a technology acceptance model to moderate the Satisfaction of Learning." IEEE Access 6 (2018): 66481-66498. https://doi. org/10.1109/access.2018.2877760

[44] Tawafak, Ragad M., Muamer N. Mohammed, Ruzaini bin Abdullah Arshah, and Awanis Romli. "Review on the effect of student learning outcome and teaching Technology in Omani's higher education Institution's academic accreditation process." In Proceedings of the 2018 7th International Conference on Software and Computer Applications, pp. 243247. 2018. https://doi.org/10.1145/3185089.3185108

[45] Tawafak, R. M., Romli, A. B., \& Arshah, R. B. A. (2019, February). E-learning Model for Students' Satisfaction in Higher Education Universities. In 2019 International Conference on Fourth Industrial Revolution (ICFIR) (pp. 1-6). IEEE. https://doi.org/10.1109/icfir. $\underline{2019.8894778}$

[46] Alfarsi, G., Sulaiman, H., Tawafak, R. M., Malik, S., Jabbar, J., \& Alsidiri, A. (2019). A Study of Learning Management System with E-Learning

[47] Tawafak, R. M., Malik, S. I., \& Alfarsi, G. (2020). Development of Framework from Adapted TAM with MOOC Platform for Continuity Intention. Development, 29(1), 16811691

[48] Tawafak, R. M., AlSideir, A., Alfarsi, G., Al-Nuaimi, M. N., Malik, S. I., \& Jabbar, J. (2019). E-learning Vs. Traditional Learning for Learners Satisfaction. E-learning, 29(3), 388-397

[49] Al Farsi, G., Jabbar, J., Tawafak, R. M., Malik, S. I., Alsidiri, A., \& Alsinani, M. (2020). Mobile Application System Supported BUC Students Services and Learning. International Journal of Interactive Mobile Technologies, 14(9). https://doi.org/10.3991/ijim.v14i09. $\underline{12053}$

[50] Tawafak, R. M., Alfarsi, G., AlNuaimi, M. N., Eldow, A., Malik, S. I., \& Shakir, M. (2020, April). Model of Faculty Experience in E-Learning Student Satisfaction. In 2020 International Conference on Computer Science and Software Engineering (CSASE) (pp. 83-87). IEEE. https://doi.org/10.1109/csase48920.2020.9142071

[51] Jabbar, J., Malik, S. I., AlFarsi, G., \& Tawafak, R. M. The Impact of WhatsApp on Employees in Higher Education. In Recent Advances in Intelligent Systems and Smart Applications (pp. 639-651). Springer, Cham. https://doi.org/10.1007/978-3-030-47411-9_34

[52] Tawafak, R. M., Buraimi, O., Jabbar, J., Alfarsi, G., Malik, S. I., Romli, A., \& Alsideiri, A. A Review Paper on Student-Graduate Advisory Expert system. https://doi.org/10.1109/iccit-144147971.2020.9213794

[53] Tawafak, R., Romli, A., Malik, S., \& Shakir, M. (2020). IT Governance Impact on Academic Performance Development. International Journal of Emerging Technologies in Learning (iJET), 15(18), 73-85. https://doi.org/10.3991/ijet.v15i18.15367

[54] Alfarsi, G., Jabbar, J., Tawafak, R. M., Malik, S. I., Alsidiri, A., \& Alsinani, M. Using Cisco Packet Tracer to simulate Smart Home. https://doi.org/10.1109 lacit47987.2019.8990975

[55] Tawafak, R., AlFarsi, G., Jabbar, J., Malik, S. I., Mathew, R., AlSidiri, A., ... \& Romli, A. (2021). Impact of Technologies During COVID-19 Pandemic for Improving Behavior Intention to Use E-learning. https://doi.org/10.3991/ijim.v15i01.17847

[56] Eldow, A., Alsharida, R. A., Hammood, M., Shakir, M., Malik, S. I., Muttar, A. K., \& Kadhim, K. A. (2021). Information Communication Technology Infrastructure in Suda- 
nese Governmental Universities. In Recent Advances in Intelligent Systems and Smart Applications (pp. 363-375). Springer, Cham. https://doi.org/10.1007/978-3-030-47411-9 20

[57] Papadakis, St. (2020). Robots and Robotics Kits for Early Childhood and First School Age. International Journal of Interactive Mobile Technologies (iJIM), 14 (18), 34-56.

[58] Nasharuddin, N., Khalid, N., \& Hussin, M. (2021). InCell VR: A Virtual Reality-based Application on Human Cell Division for Mobile Learning. iJIM, 15(02), 55. https://doi.org/10.3991/ijim.v15i02.18049

\section{Authors}

Sohail Iqbal Malik obtained his $\mathrm{PhD}$. Degree in computer science from Deakin University, Australia in 2016. His area of interest includes algorithmic thinking, ELearning, Mobile Application, and computer education.

Ragad M Tawafak is PhD. Degree in computer science, 2020 Malaysia. She is an expert in E-Learning, Mobile Application, Knowledge Management, etc.

Ghaliya Alfarsi is MSc. Degree in computer science, 2015, Oman. She is an expert in E-Learning, Mobile Application, Knowledge Management, etc.

Roy Mathew is a PhD in Computer science, 2016, India. He is an expert in ELearning, Mobile Application, Knowledge Management, etc.

Mohammed Waseem Ashfque is post-graduation in Computer Science from $\mathrm{Dr}$ Babasaheb Ambedkar Marathwada University, India. His research domain is Artificial intelligence, Machine learning, and Deep Learning. He has sound experience in teaching at various colleges and Universities.

Article submitted 2020-12-18. Resubmitted 2021-02-03. Final acceptance 2021-02-03. Final version published as submitted by the authors. 